\title{
Concept for Mathematical Models for Subprocesses in the Manufacture of Particleboards
}

\author{
Carina Pöll ${ }^{1 *}$, Martin Riegler ${ }^{1}$, Felix Breitenecker ${ }^{2}$ \\ ${ }^{1}$ Kompetenzzentrum Holz GmbH, Austria, *c.poell@kplus-wood.at \\ ${ }^{2}$ Institute of Analysis and Scientific Computing, TU Wien, Austria
}

SNE 28(3), 2018, 105 - 107, DOI: 10.11128/sne.28.sn.10428

Received: Sept. 15, 2016 (Selected EUROSIM Congress 2016

Postconf. Publ.), Revised July 30, Accepted: August 25, 2018

SNE - Simulation Notes Europe, ARGESIM Publisher Vienna,

ISSN Print 2305-9974, Online 2306-0271, www.sne-journal.org

Abstract. In this paper a concept for modelling selected sub-processes of the manufacturing process of particleboards is presented. First, the entire process is described briefly, and then special attention is on the stages drying and pressing. Afterwards models for the dryer and press from literature are discussed. Furthermore, a concept for the planned models of the selected stages is presented. The future objective is to use the developed models of different stages of the manufacturing process to control the process using statistical models. Thus the impact of potential measures can be simulated. Finally there is a short conclusion including an outlook on future work.

\section{Introduction}

The particleboard was invented by Max Himmelheber and he took out patents since the beginning of the fifties, see (Jägersberg, 2004). The industrial manufacturing process of particleboards consists of several consecutive sub processes. The quality of the produced particleboard depends on the raw material and the different processing steps. To ensure a high quality of the final product, while optimizing the use of energy and resources, adjustable process parameters need to be continuously adapted (Riegler et al, 2013). Previous simulations of potential measures can predict the impact of these measures and hence avoid possible costs of rejects.
Therefore, models with different levels of detail of selected steps for the entire process need to be considered. By modelling the entire process, the interactions between different process stages can be studied. This generates a deeper understanding of the manufacturing process and enables a more efficient usage of resources. In this paper, mathematical models for two important process steps of the manufacturing process of particleboards are discussed.

\section{Manufacturing Process of Particleboards}

The description of the manufacturing process is mainly based on (Rowell, 2013). In general, round wood, wood residues and recovered wood are used for the production of particleboards. The amount of these raw materials depends on the availability, the system specifications and the type of the produced particleboard. Based on (Wagenführ, 2012) in Fig. 1, a schematic representation of the manufacturing process of particleboards is depicted. The considered process is called flat pressing process, i.e. the mattress passes the press horizontally. A particleboard consists of three layers. On the one hand the so-called surface layers, which in general constitute of fine particles, and on the other hand the core layer, where the larger particles are used. Therefore the sorting of the particles in different fractions is an important step. The resin metering is different for the surface and core layers due to the differences of the used particles. There are different adhesives, which can be used for the production. In most cases, urea-formaldehyde (UF) resin is used for the production. 


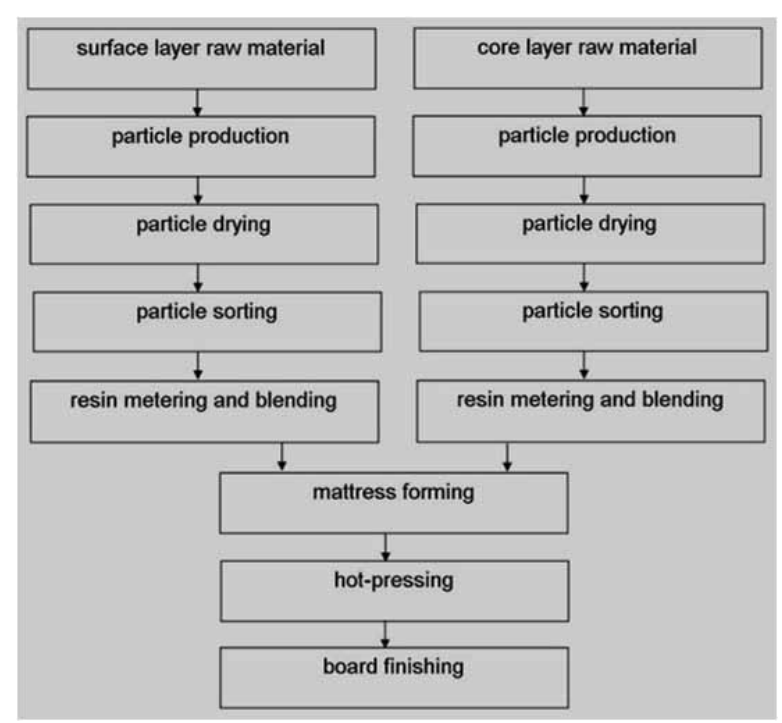

Figure 1. Manufacturing process of particleboards based on (Wagenführ, 2012).

Two stages of the manufacturing process are considered in more detail in the following.

\subsection{Dryer}

The moisture content of the particles is a crucial feature for the manufacturing process. Therefore, the drying is an important step. There are different types of dryers. One of the main differences is the method of heating. The two possibilities are direct or indirect heat, which, inter alia, cause different temperatures resulting in different drying processes, see (Wagenführ, 2012).

\subsection{Press}

The two important characteristics during pressing are temperature and pressure. These two factors influence the density of the product and the resin hardening during pressing. There are different types of presses: batch presses and continuous presses. In Fig. 2 a schematic illustration of a continuous press is depicted.

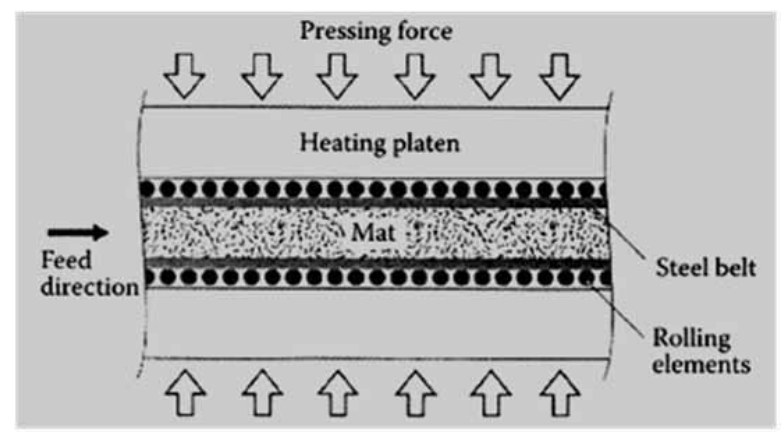

Figure 1. Schematic description of a continuous press (Rowell, 2013).

\section{Mathematical Model}

\subsection{Dryer}

In (Whitaker, 1977) based on the transport equations for continuous media, a theory of the simultaneous heat, mass and momentum transfer for porous media was developed. Two of the used equations are

- Darcy's law:

$$
q=-\frac{\kappa}{\mu}(\nabla p-\rho g)
$$

- Fick's law:

$$
\frac{\partial \varphi}{\partial t}=D \frac{\partial^{2} \varphi}{\partial x^{2}}
$$

The findings of (Whitaker, 1977) are used in (Younsi et $a l, 2006$ ) (heat and mass transfer during heat treatment of wood), (Perre, 1999) (3D drying model for porous media) and (Torres et al, 2011) (vacuum drying of wood), where models for different applications are developed. For the most applications in drying, different moisture phases (free water, bound water and water vapor) have to be considered. In (Fyhr, 1997) a twodimensional model for drying wood chips in superheated steam and especially under conditions in a pneumatic convective dryer is presented.

Based on models from literature, the decisive factors for modelling the drying of particles are worked out. Using these characteristics and the underlying physical laws, a model for the dryer will be developed. There will be a distinction of direct and indirect heat for the simulations. Furthermore, a more detailed model will include properties of the particles like for example the size. The goal of these simulations is to compute the moisture content of the particles. The dryer is rather at the beginning of the whole manufacturing process, therefore the moisture content is a state variable, which is important for most of the following steps.

\subsection{Press}

In (Thömen, 2010) a model of a hot-press is described. This model consists of three main parts: coupled heat and mass transfer, material compression, resin hardening. The simulation of the heat and mass transfer is realized using an approach based on finite-volume method. The simulation was applied on the manufacturing of medium-density fiberboards (MDF). 
The manufacturing process of MDF is similar to the process of particleboards, which is described in Fig. 1. The output of the simulation is the internal bond depending on the position in the mattress over the course of the hot-pressing process. The results of the simulation were compared with experimental results of onelayered MDF boards, produced in laboratory scale.

The moisture content of particles, which is computed with the model of the dryer, will be included in the model of the hot-press, i.e. the moisture content of the particles is an input variable for the model of the press. Moreover the geometry of the particles and the structure of the mattress are used for a detailed simulation of the hot-pressing. Using the structure of the mattress, the motion of steam during pressing can be simulated.

\section{Conclusion}

By means of the dryer and press it was shown, that there exist many models for different stages of the production of particleboards. To analyze the combination of physical processes, the connection of different models is considered to be crucial. By using strict input-output relations for the coupling of the different model parts it is possible to extend the model by including more and more production steps and also to use models with different levels of detail. Future work will include modelling of processes at different levels of detail and additional stages within the manufacturing process. The aim is to build a simulation of the most important steps of the process. It is planned to validate model results using experiments (laboratory or industrial scale). Based on the results of the models of the physical processes during the manufacturing of particleboards, statistical models for process control are computed similar to (Riegler et al, 2013).

\section{References}

[1] Fyhr C, Rasmuson A. "Some aspects of the modelling of wood chipy drying in superheated steam", International journal of heat and mass transfer, vol. 40(12), pp. 28252842, 1997.

[2] Jägersberg O. "Max Himmelheber zum 100. Geburtstag", Germany: Hirzel, 2004, p. 413 ff.

[3] Perré P, Turner IW. "A 3-D version of TransPore: a comprehensive heat and mass transfer computational model for simulating the drying of porous media", International Journal of heat and mass transfer, vol. 42(24), pp. 4501-4521, 1999.
[4] Riegler M, Spangl B, Weigl M, Wimmer R, Müller U. "Simulation of a real-time process adaptation in the manufacture of high-density fibreboards using multivariate regression analysis and feedforward control", Wood Science and Technology, vol. 47, pp. 1243-1259, 2013.

[5] Rowell RM. "Handbook of Wood Chemistry and Wood Composites", $2^{\text {nd }}$ ed., USA: CRC Press Taylor \& Francis Group, 2013, pp. 326-364.

[6] Thömen H. "Vom Holz zum Werkstoff - Grundlegende Untersuchungen zur Herstellung und Struktur von Holzwerkstoffen", Schweiz, 2010.

[7] Torres Ss, Jomaa W, Puiggali J-R, Avramidis S. "Multiphysics modeling of vacuum drying of wood", Applied Mathematical Modelling, vol. 35(10), pp. 5006-5016, 2011.

[8] Wagenführ A, Scholz F. "Taschenbuch der Holztechnik”, $2^{\text {nd }}$ ed., Germany: Carl Hanser Verlag GmbH \& Co. KG, 2012, pp. 206-231.

[9] Whitaker S. "Simultaneous Heat, Mass, and Momentum Transfer in Porous Media: A Theory of Drying", Adv. Heat Transfer, vol. 13, pp. 119-200, 1977.

[10] Younsi R, Kocaefe D, Poncsak S, Kocaefe Y. "Computational modelling of heat and mass transfer during the high-temperature heat treatment of wood", Applied thermal engineering, vol. 27(8), pp. 1424-1431, 2006. 